\title{
Metode Rapid Application Development (RAD) pada Perancangan Website Inventory PT. SARANA ABADI MAKMUR BERSAMA (S.A.M.B) JAKARTA
}

\author{
${ }^{1)}$ Oky Irnawati, ${ }^{2)}$ Galih Bayu Aji Listianto \\ ${ }^{1)}$ Manajemen Informatika, AMIK BSI Bekasi \\ oky.okt@bsi.ac.id \\ ${ }^{2)}$ Manajemen Informatika, AMIK BSI Bekasi \\ dholoylistianto@gmail.com
}

\begin{abstract}
PT. S.A.M.B (Sarana Abadi Makmur Bersama) is a distributor and logistics company engaged in Modern Trade (MT) for fast moving consumer goods (FMCG) in Jabodetabek (Jakarta, Bogor, Depok, Tangerang, Bekasi). In addition to distribution, SAMB also provides services for companies seeking logistics and transportation services for modern trade within the designated area. The inventory design system is one of the most important factors in meeting the needs of consumers in a timely and demanding manner. There are still many companies that use desktop applications especially on PT. Sarana Abadi Makmur Bersama. Employees often complain about the performance of the used desktop app. Not all desktop applications can run on all operating systems, while web applications can run in all operating systems as long as there is a browser and an internet connection, it makes it more practical. With web-based asset inventory data item can be used relatively fast, relatively accurate, and relatively more accurate data.
\end{abstract}

\section{Keywords: Rapid Application Development, Web-Based Inventory Program Design}

Abstrak - PT. S.A.M.B (Sarana Abadi Makmur Bersama) adalah perusahaan distributor dan logistik yang bergerak dalam bidang Modern Trade (MT) untuk fast moving consumers goods (FMCG) di wilayah Jabodetabek (Jakarta, Bogor, Depok, Tangerang, Bekasi). Selain distribusi, SAMB juga menyediakan layanan bagi perusahaan yang mencari jasa logistik dan transportasi untuk perdagangan modern dalam area yang ditentukan. Perancangan sistem inventory menjadi salah satu faktor yang paling penting dalam memenuhi kebutuhan konsumen dalam waktu yang tepat dan sesuai dengan permintaan. Masih banyak perusahaan-perusahaan yang menggunakan aplikasi desktop terutama pada PT. Sarana Abadi Makmur Bersama. Para karyawan sering mengeluhkan kinerja dari aplikasi desktop yang dipakai. Tidak semua aplikasi desktop dapat berjalan di semua Sistem Operasi, sedangkan aplikasi web dapat berjalan disemua Sistem Operasi selama ada browser dan koneksi internet, itu membuatnya lebih praktis. Dengan berbasis web, data inventori asset barang dapat digunakan relatif cepat, relatif tepat, dan relatif data lebih akurat.

\section{Kata Kunci: Rapid Application Development, Perancangan Website Inventory.}

\section{A. PENDAHULUAN}

Aplikasi berbasis web saat ini lebih diminati dibanding aplikasi yang masih berbasis dekstop. Hal ini berkaitan dengan begitu pesatnya kemajuan teknologi internet. Dapat diakses dimana saja, merupakan salah satu keunggulan dari internet. Aplikasi berbasis web yang menjalankannya dibutuhkan koneksi internet, membuatnya lebih diminati karena dapat diakses dimana saja. Tidak seperti aplikasi desktop yang terbatas pada laptop atau PC.

Sistem perancangan inventory menjadi salah satu faktor yang paling penting dalam memenuhi kebutuhan konsumen dalam waktu yang tepat dan sesuai dengan permintaan (Prasetio, 2014). Tidak semua aplikasi desktop dapat berjalan di semua Sistem Operasi, sedangkan aplikasi web dapat berjalan disemua Sistem Operasi selama ada browser dan koneksi internet, itu membuatnya lebih praktis. Aplikasi desktop pun membutuhkan instalasi dan upgrade pada setiap Client sementara aplikasi web hanya membutuhkan upgrade pada sisi Server. Otomatis biaya perawatan aplikasi web menjadi lebih ringan.

Masih banyak perusahaan-perusahaan yang menggunakan aplikasi desktop terutama pada PT. Sarana Abadi Makmur Bersama (S.A.M.B). PT. S.A.M.B (Sarana Abadi Makmur Bersama) adalah perusahaan distributor dan logistik yang bergerak dalam bidang Modern Trade (MT) untuk fast moving consumers goods (FMCG) di wilayah Jabodetabek (Jakarta, Bogor, Depok, Tangerang, Bekasi). Selain distribusi, SAMB juga menyediakan layanan bagi perusahaan yang mencari jasa logistik dan transportasi 
untuk perdagangan modern dalam area yang ditentukan. Para karyawan sering mengeluhkan kinerja dari aplikasi desktop yang dipakai. Dalam aplikasi tersebut tidak bisa menyimpan data dan informasi secara terpusat pada suatu basis data, sehingga sering terjadi ketidaksesuaian informasi dan kehilangan data yang disebabkan oleh kesalahan manusia (Mersiana \& Purwandari, 2017). Dengan berbasis web, data inventory dapat digunakan relatif cepat, relatif tepat, dan relatif data lebih akurat (Frieyadie, 2015).

Sistem yang memiliki tingkat kedinamisan yang tinggi, ketersediaan waktu dan anggran biaya pengembangan yang terbatas, untuk kebutuhan informasi terkini secara cepat, dan perlunya kedekatan interaksi hubungan yang personal dengan karakteristik penggunanya lebih tepat menerapkan metode RAD (Kosasi \& Yuliani, 2015)

B. TINJAUAN PUSTAKA

1. Persediaan Barang

Teori persediaan menurut (Kusuma, 2009) mengatakan "persediaan didefinisikan sebagai barang yang disimpan untuk digunakan atau dijual pada periode mendatang".

2. Website

www (World Wide Web) atau biasanya yang dikenal dengan web merupakan salah satu fasilitas diinternet yang berfungsi sebagai media interaksi pemakai komputer untuk menampilkan halaman informasi yang dicari. Halaman web tersebut diakses dan dibaca menggunakan perangkat lunak web browser seperti internet explorer, mozilla firefox, google chrome, dan sebagainya.

3. Peralatan Pendukung

Dalam proses pembuatan website dibutuhkan peralatan pendukung untuk merancang sistem diantaranya Use Case, Activity Diagram, Entity Relationship Diagram (ERD) dan Logical Record Structure (LRS).

a) Use Case

"Merupakan pemodelan untuk kelakuan (behavior) sistem informasi yang akan dibuat. Secara kasar, use case digunakan untuk mengetahui fungsi apa saja yang ada di dalam sebuah sistem informasi dan siapa saja yang berhak menggunakan fungsi-fungsi itu" (Sukamto \& Shalahudin, 2016).

b) Activity Diagram

"Menggambarkan workflow (aliran kerja) atau aktivitas dari sebuah sistem atau proses bisnis atau menu yang ada pada perangkat lunak" (Sukamto

$\&$

Shalahudin, 2016)

c) Entity Relationship Diagram (ERD)

Pemodelan awal basis data yang paling banyak digunakan adalah menggunakan

Entity Relationship Diagram (ERD). ERD dikembangkan berdasarkan teori himpunan dalam bidang matematika. ERD digunakan untuk pemodelan basis data relasional. (Sukamto \& Shalahudin, 2016)

d) Logical Record Structure (LRS)

Menurut (Andriansyah, 2016) "LRS merupakan transformasi dari penggambaran ERD dalam bentuk yang paling jelas dan mudah untuk dipahami".

\section{METODE PENELITIAN}

Metode dalam penelitian ini menggunakan metode pengembangan perangkat lunak dan metode pengumpulan data.

1. Metode Pengembangan Perangkat Lunak Rapid Application Development (RAD) adalah model proses pengembangan perangkat lunak yang bersifat incremental terutama untuk waktu pengerjaan yang pendek.(Sukamto \& Shalahudin, 2016).

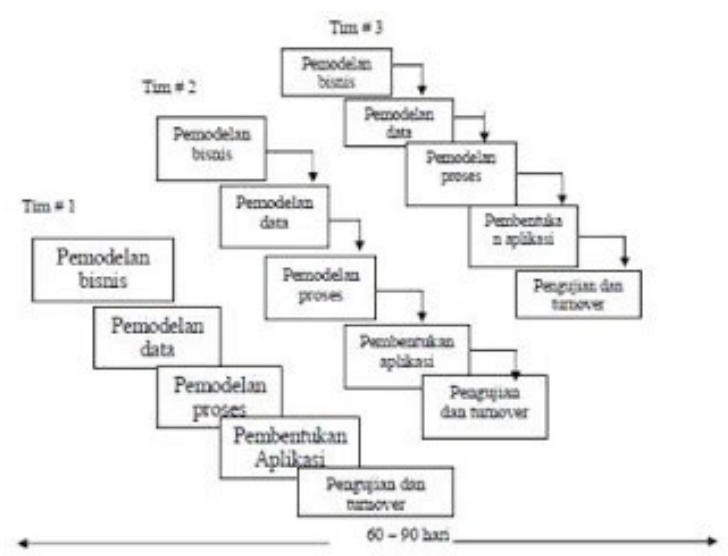

Sumber: (Sukamto \& Shalahudin, 2016)

Gambar 1. llustrasi Model RAD

a) Pemodelan Bisnis

Pemodelan yang dilakukan untuk memodelkan fungsi bisnis untuk mengetahui informasi apa saja yang harus dibuat, siapa yang harus membuat informasi itu, bagaimana alur informasi itu, proses apa saja yang terkait informasi itu.

Tahapan ini penulis mengumpulkan bahan-bahan serta melakukan pengamatan terhadap kebutuhan aplikasi berbasis website dibanding dengan aplikasi berbasis desktop. 
Informasi tersebut dianalisis untuk mendapatkan spesifikasi sistem.

b) Pemodelan Data

Memodelkan data apa saja yang dibutuhkan berdasarkan pemodelan bisnis dan mendefinisikan atributatributnya beserta relasinya dengan data-data yang lain.

Tahapan ini penulis menggunakan ERD dan $L R S$ untuk pemodelan basis data sehingga dapat diketahui atribut apa saja yang diperlukan dan bagaimana relasi datanya.

c) Pemodelan Proses

Mengimplementasikan fungsi bisnis yang sudah didefinisikan terkait dengan pendefinisian data.

Tahapan ini penulis menggunakan use case sebagai identifikasi proses bisnis dan activity diagram sebagai pemodelan proses bisnis.

d) Pembuatan Aplikasi

Mengimplementasikan pemodelan proses dan data menjadi program. Model RAD sangat menganjurkan pemakaian komponen yang sudah ada jika dimungkinkan.

Tahapan ini penulis melakukan pemrograman aplikasi dengan bahasa pemrograman PHP, HTML, dan CSS sesuai dengan desain yang telah dibuat.

e) Pengujian dan pergantian

Menguji komponen-komponen yang dibuat. Jika sudah teruji maka tim pengembang komponen dapat beranjak untuk mengembangkan komponen berikutnya.

Tahapan ini dilakukan pengujian menggunakan blackbox testing untuk mengetahui apakah sudah bisa beroperasi dengan baik atau tidak.

2. Metode Pengumpulan Data

Teknik pengumpulan data yang digunakan oleh penulis dalam penelitian ini adalah:

a) Observasi

Penulis melakukan pengamatan langsung pada PT. Sarana Abadi Makmur Bersama di Pulo Gebang Jakarta Timur pada bagian admin gudang. Penulis mengamati sistem penerimaan barang serta gudang yang berjalan di PT SAMB. Hasil dari pengamatan tersebut langsung dicatat oleh penulis dan dari kegiatan pengamatan dapat diketahui kesalahan atau proses dan kegiatan tersebut.

b) Wawancara
Penulis melakukan wawancara terhadap ibu Tri Cahyani Oktavia selaku Ketua Bagian Administrasi mengenai jalannya proses penerimaan barang dari supplier sampai pengiriman barang ke pelanggan. Penulis juga melakukan wawancara terhadap beberapa karyawan pada PT. SAMB mengenai program yang sudah dipakai.

c) Studi Pustaka

Selain melakukan kegiatan wawancara dan pengamatan penulis juga melakukan studi kepustakaan melalui referensi-referensi yang ada di perpustakaan, internet atau di tempat lain.

\section{HASIL DAN PEMBAHASAN}

1. Pemodelan Bisnis Berdasarkan analisa di dapatkan tiga pengguna yang dapat mengakses sistem yaitu karyawan, ketua dan admin.

a. Analisa Kebutuhan Karyawan

1) Karyawan dapat menambah dan mengubah data supplier.

2) Karyawan dapat menginput data barang masuk.

3) Karyawan dapat menginput data barang keluar.

4) Karyawan dapat mencetak good receive, sales order, dan purchase order

5) Karyawan dapat menambah dan mengubah data toko/pelanggan

b. Analisa Kebutuhan Ketua

1) Ketua dapat melakukan semua yang dapat dilakukan karyawan.

2) Ketua dapat menghapus data supplier, stok dan data toko.

3) Ketua dapat mencetak laporan semua data

c. Analisa Kebutuhan Admin

1) Admin dapat melakukan semua yang dapat dilakukan Ketua.

2) Admin dapat menambah, mengubah dan menghapus data pengguna

2. Pemodelan Data
a) Entity Relationship Diagram (ERD) 


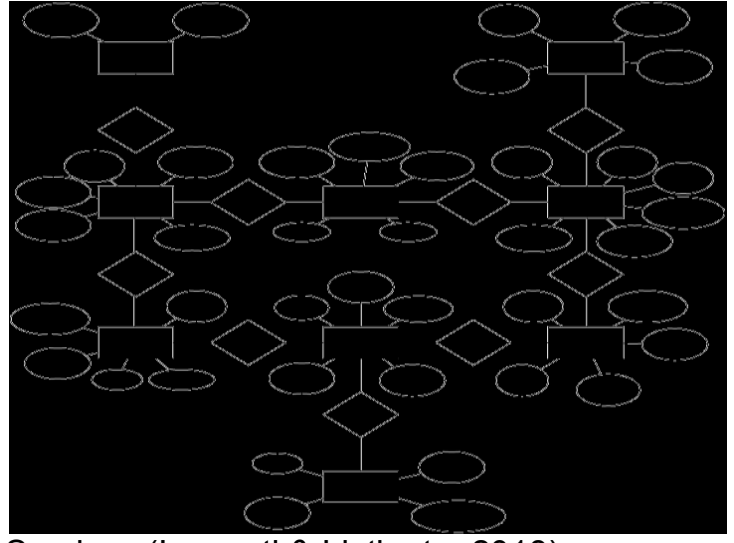

Sumber: (Irnawati \& Listianto, 2018)

Gambar 2. ERD Inventory

b) Logical Record Structure (LRS)

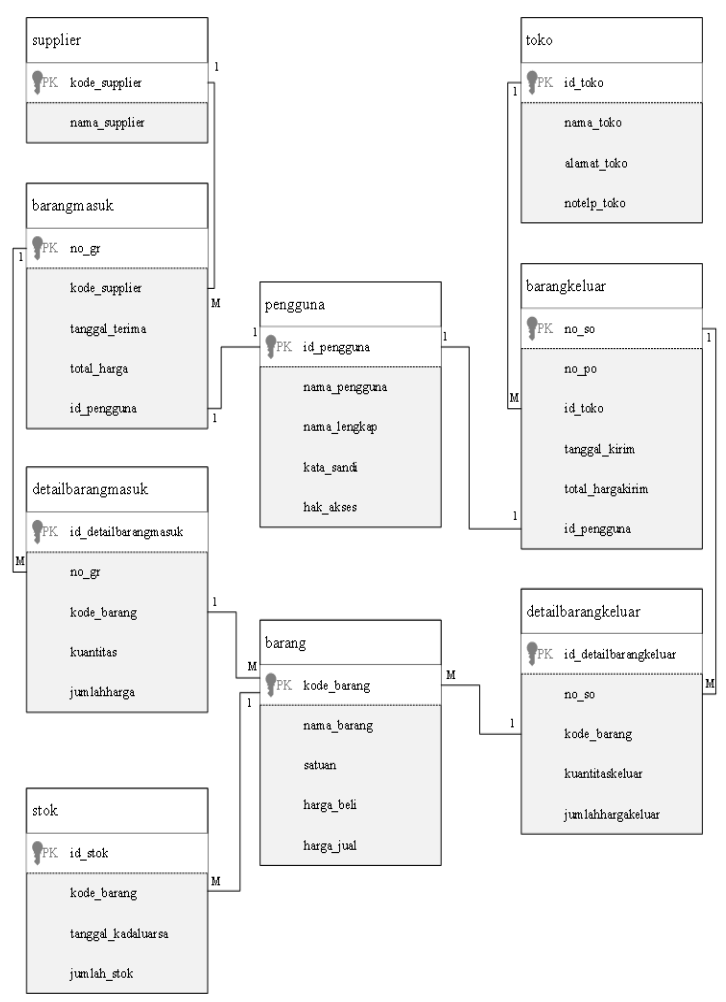

Sumber: (Irnawati \& Listianto, 2018)

Gambar 3. LRS Inventory

3. Pemodelan Proses

a) Use Case

Use case Perancangan Website Inventory PT. Sarana Abadi Makmur Bersama (S.A.M.B) Jakarta

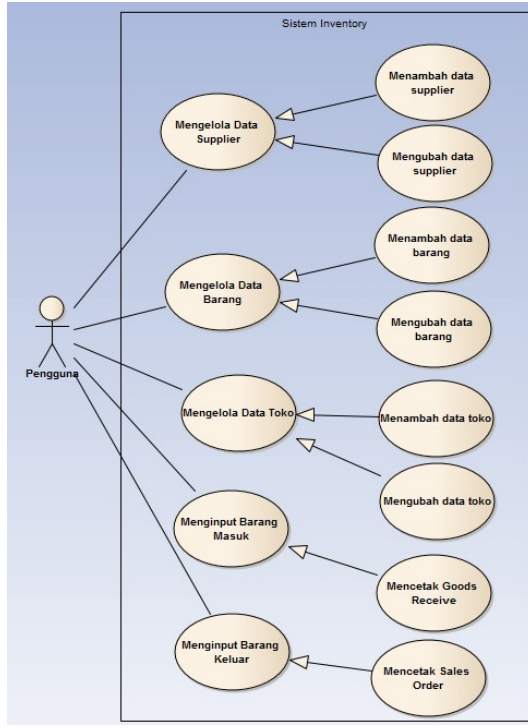

Sumber: (Irnawati \& Listianto, 2018)

\section{Gambar 4. Use Case Inventory}

b) Activity Diagram

Activity Diagram Perancangan Website Inventory PT. Sarana Abadi Makmur Bersama (S.A.M.B) Jakarta.

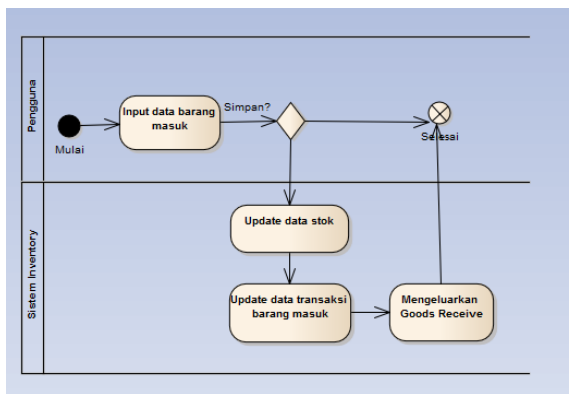

Sumber: (Irnawati \& Listianto, 2018)

Gambar 5. Activity Diagram Barang Masuk

4. Pembuatan Aplikasi

Implementasi Perancangan Website Inventory PT. Sarana Abadi Makmur Bersama (S.A.M.B) Jakarta

a) Halaman Input Barang Masuk

Barang masuk diinput oleh karyawan secara terkomputerisasi melalui halaman input barang masuk. Data yang dibutuhkan berupa kode supplier, nama barang, satuan, harga, tanggal kadaluarsa, kuantitas dan jumlah harga. 


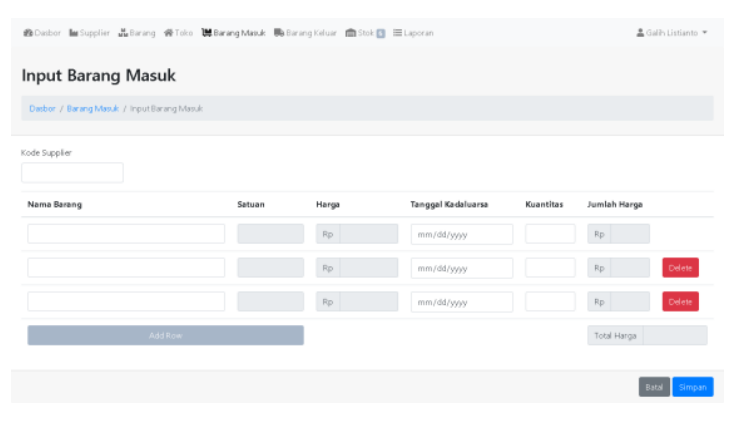

Sumber: (Irnawati \& Listianto, 2018)

Gambar 6. Tampilan Halaman Input Barang Masuk

b) Halaman Input Barang Keluar Barang keluar diinput oleh karyawan secara terkomputerisasi melalui halaman input barang keluar. Data yang dibutuhkan berupa kode toko, nama barang, satuan, harga, kuantitas, stok dan jumlah harga.

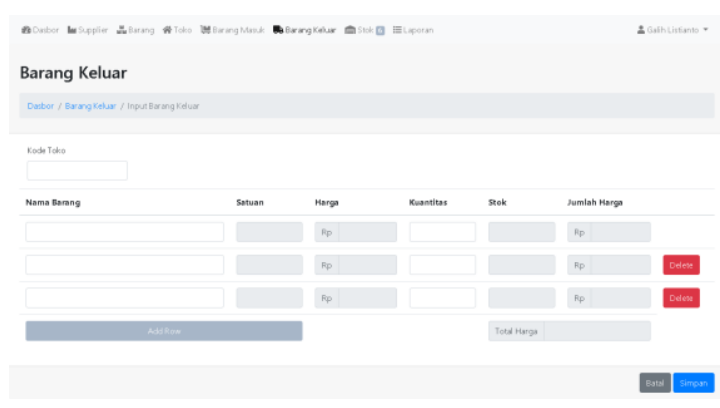

Sumber: (Irnawati \& Listianto, 2018)

Gambar 7. Tampilan Halaman Input Barang Keluar

c) Nota Penerimaan Barang (Goods Receive)

Hasil dari halaman input barang masuk berupa Nota penerimaan barang untuk supplier.
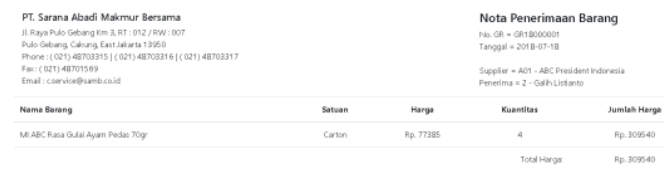

Sumber: (Irnawati \& Listianto, 2018)

Gambar 8. Tampilan Nota Penerimaan

\section{Barang}

d) Sales Order

Hasil dari halaman input barang keluar berupa Sales Order untuk toko atau customer.
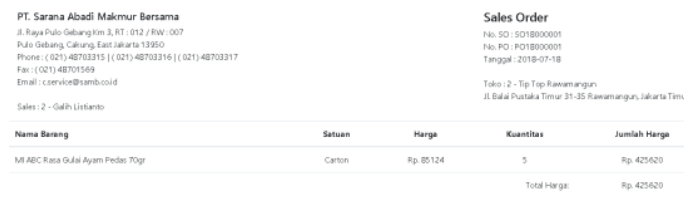

Sumber: (Irnawati \& Listianto, 2018)

Gambar 9. Tampilan Sales Order

5. Pengujian dan pergantian

Pengujian terhadap program yang dibuat menggunakan blackbox testing yang fokus terhadap proses masukan program.

a) Pengujian Halaman Input Barang Masuk

Tabel 1. Hasil Pengujian Blackbox Testing Halaman Input Barang Masuk

\begin{tabular}{|c|c|c|c|c|c|}
\hline $\begin{array}{l}\mathrm{N} \\
\mathrm{O}\end{array}$ & $\begin{array}{l}\text { Seke } \\
\text { nario } \\
\text { Peng } \\
\text { ujian }\end{array}$ & $\begin{array}{l}\text { Test } \\
\text { Case }\end{array}$ & $\begin{array}{c}\text { Hasil } \\
\text { yang } \\
\text { Diharap } \\
\text { kan }\end{array}$ & $\begin{array}{l}\text { Hasil } \\
\text { Peng } \\
\text { ujian }\end{array}$ & $\begin{array}{c}\text { Kes } \\
\text { imp } \\
\text { ula } \\
n\end{array}$ \\
\hline 1 & $\begin{array}{l}\text { Klik } \\
\text { Simp } \\
\text { an } \\
\text { tanpa } \\
\text { mengi } \\
\text { si } \\
\text { semu } \\
\text { a } \\
\text { textbo } \\
x\end{array}$ & $\begin{array}{l}\text { Kode } \\
\text { Suppli } \\
\text { er: } \\
\text { (koson } \\
\text { g) } \\
\text { Semua } \\
\text { textbo } \\
x \text { data } \\
\text { barang } \\
\vdots \\
\text { (koson } \\
\text { g) }\end{array}$ & $\begin{array}{l}\text { Sistem } \\
\text { tidak } \\
\text { akan } \\
\text { mempro } \\
\text { ses dan } \\
\text { muncul } \\
\text { pesan } \\
\text { "Harus } \\
\text { Diisi." }\end{array}$ & $\begin{array}{c}\text { Sesu } \\
\text { ai } \\
\text { Hara } \\
\text { pan }\end{array}$ & $\begin{array}{c}\text { Vali } \\
\text { d }\end{array}$ \\
\hline 2 & $\begin{array}{l}\text { Mengi } \\
\text { si } \\
\text { semu } \\
\text { a } \\
\text { textbo } \\
x \\
\text { kecua } \\
\text { li } \\
\text { salah } \\
\text { satu } \\
\text { textbo } \\
x \\
\text { dibiar } \\
\text { kan } \\
\text { koson } \\
\text { g lalu } \\
\text { klik } \\
\text { Simp } \\
\text { an }\end{array}$ & $\begin{array}{l}\text { Kode } \\
\text { Suppli } \\
\text { er: } \\
\text { (koson } \\
\text { g) } \\
\text { Semua } \\
\text { textbo } \\
x \text { data } \\
\text { barang } \\
\text { diisi }\end{array}$ & $\begin{array}{l}\text { Sistem } \\
\text { tidak } \\
\text { akan } \\
\text { mempro } \\
\text { ses dan } \\
\text { muncul } \\
\text { pesan } \\
\text { "Kode } \\
\text { Supplier } \\
\text { Harus } \\
\text { Diisi." }\end{array}$ & $\begin{array}{c}\text { Sesu } \\
\text { ai } \\
\text { Hara } \\
\text { pan }\end{array}$ & $\begin{array}{c}\text { Vali } \\
\text { d }\end{array}$ \\
\hline 3 & $\begin{array}{l}\text { Mengi } \\
\text { si } \\
\text { textbo } \\
x \\
\text { kuanti } \\
\text { tas } \\
\text { deng }\end{array}$ & $\begin{array}{l}\text { kuantit } \\
\text { as: } \\
\text { qwerty }\end{array}$ & $\begin{array}{l}\text { textbox } \\
\text { kuantita } \\
\text { s tidak } \\
\text { akan } \\
\text { teriisi }\end{array}$ & $\begin{array}{c}\text { Sesu } \\
\text { ai } \\
\text { Hara } \\
\text { pan }\end{array}$ & $\begin{array}{c}\text { Vali } \\
\text { d }\end{array}$ \\
\hline
\end{tabular}




\begin{tabular}{|c|l|l|l|l|l|}
\hline & $\begin{array}{l}\text { an } \\
\text { huruf }\end{array}$ & & & & \\
\hline 4 & Mengi & kode & Sistem & Sesu & Vali \\
si & supplie & aidak & d \\
kode & r: & akan & Hara \\
suppli & abcdef & \\
mempro & pan & \\
& er & ghi & ses dan & & \\
yang & Semua & muncul & & \\
tidak & textbo & pesan & & \\
ada & x data & "Ada & & \\
dalam & barang & data & & \\
data & sesuai & yang & & \\
suppli & & tidak & & \\
er (di & & diketahu & & \\
datab & & i." & & \\
ase) & & & & \\
\hline
\end{tabular}

b) Pengujian Halaman Input Barang Keluar

Tabel 2. Hasil Pengujian Blackbox Testing Halaman Input Barang Keluar

\begin{tabular}{|c|c|c|c|c|c|}
\hline $\begin{array}{l}N \\
0\end{array}$ & $\begin{array}{l}\text { Seke } \\
\text { nario } \\
\text { Peng } \\
\text { ujian }\end{array}$ & $\begin{array}{l}\text { Test } \\
\text { Case }\end{array}$ & $\begin{array}{c}\text { Hasil } \\
\text { yang } \\
\text { Diharap } \\
\text { kan }\end{array}$ & $\begin{array}{l}\text { Hasil } \\
\text { Peng } \\
\text { ujian }\end{array}$ & $\begin{array}{c}\text { Kes } \\
\text { imp } \\
\text { ula } \\
n\end{array}$ \\
\hline 1 & $\begin{array}{l}\text { Klik } \\
\text { Simp } \\
\text { an } \\
\text { tanp } \\
\text { a } \\
\text { men } \\
\text { gisi } \\
\text { semu } \\
\text { a } \\
\text { textb } \\
\text { ox }\end{array}$ & $\begin{array}{l}\text { Kode } \\
\text { Toko: } \\
\text { (koson } \\
\text { g) } \\
\text { Semua } \\
\text { textbo } \\
x \text { data } \\
\text { barang } \\
: \\
\text { (koson } \\
\text { g) }\end{array}$ & $\begin{array}{l}\text { Sistem } \\
\text { tidak } \\
\text { akan } \\
\text { mempro } \\
\text { ses dan } \\
\text { muncul } \\
\text { pesan } \\
\text { "Harus } \\
\text { Diisi." }\end{array}$ & $\begin{array}{c}\text { Sesu } \\
\text { ai } \\
\text { Hara } \\
\text { pan }\end{array}$ & $\begin{array}{c}\text { Vali } \\
\text { d }\end{array}$ \\
\hline 2 & $\begin{array}{l}\text { Men } \\
\text { gisi } \\
\text { semu } \\
\text { a } \\
\text { textb } \\
\text { ox } \\
\text { kecu } \\
\text { ali } \\
\text { salah } \\
\text { satu } \\
\text { textb } \\
\text { ox } \\
\text { dibiar } \\
\text { kan } \\
\text { koso } \\
\text { ng } \\
\text { lalu } \\
\text { klik } \\
\text { Simp } \\
\text { an }\end{array}$ & $\begin{array}{l}\text { Kode } \\
\text { Toko: } \\
\text { (koson } \\
\text { g) } \\
\text { Semua } \\
\text { textbo } \\
x \text { data } \\
\text { barang } \\
\text { diisi }\end{array}$ & $\begin{array}{l}\text { Sistem } \\
\text { tidak } \\
\text { akan } \\
\text { mempro } \\
\text { ses dan } \\
\text { muncul } \\
\text { pesan } \\
\text { "Kode } \\
\text { Toko } \\
\text { Harus } \\
\text { Diisi." }\end{array}$ & $\begin{array}{c}\text { Sesu } \\
\text { ai } \\
\text { Hara } \\
\text { pan }\end{array}$ & $\begin{array}{c}\text { Vali } \\
\text { d }\end{array}$ \\
\hline
\end{tabular}

\begin{tabular}{|c|c|c|c|c|c|}
\hline 3 & $\begin{array}{l}\text { Men } \\
\text { gisi } \\
\text { textb } \\
\text { ox } \\
\text { kuant } \\
\text { itas } \\
\text { deng } \\
\text { an } \\
\text { huruf }\end{array}$ & $\begin{array}{l}\text { kuantit } \\
\text { as: } \\
\text { qwerty }\end{array}$ & $\begin{array}{l}\text { textbox } \\
\text { kuantita } \\
\text { s tidak } \\
\text { akan } \\
\text { teriisi }\end{array}$ & $\begin{array}{c}\text { Sesu } \\
\text { ai } \\
\text { Hara } \\
\text { pan }\end{array}$ & $\begin{array}{c}\text { Vali } \\
\text { d }\end{array}$ \\
\hline 4 & $\begin{array}{l}\text { Men } \\
\text { gisi } \\
\text { kode } \\
\text { Toko } \\
\text { yang } \\
\text { tidak } \\
\text { ada } \\
\text { dala } \\
\text { m } \\
\text { data } \\
\text { toko } \\
\text { (di } \\
\text { dala } \\
\text { m } \\
\text { data } \\
\text { base } \\
\text { ) }\end{array}$ & $\begin{array}{l}\text { kode } \\
\text { Toko: } \\
\text { abcdef } \\
\text { ghi } \\
\text { Semua } \\
\text { textbo } \\
x \text { data } \\
\text { barang } \\
\text { sesuai }\end{array}$ & $\begin{array}{l}\text { Sistem } \\
\text { tidak } \\
\text { akan } \\
\text { mempro } \\
\text { ses dan } \\
\text { muncul } \\
\text { pesan } \\
\text { "Ada } \\
\text { data } \\
\text { yang } \\
\text { tidak } \\
\text { diketahu } \\
\text { i." }\end{array}$ & $\begin{array}{c}\text { Sesu } \\
\text { ai } \\
\text { Hara } \\
\text { pan }\end{array}$ & $\begin{array}{c}\text { Vali } \\
\text { d }\end{array}$ \\
\hline
\end{tabular}

\section{E. KESIMPULAN DAN SARAN}

1. Kesimpulan

Setelah melakukan analisa, perancangan, serta implementasi untuk program inventory berbasis web pada PT. Sarana Abadi Makmur Bersama, maka dapat disimpulkan sebagai berikut:

a) Program inventory ini merupakan aplikasi sistem komputerisasi yang dibuat berbasis web dan memuat database pengolahan data secara terpusat sehingga dapat mengolah database tersebut menjadi informasi yang dibutuhkan oleh para pengguna.

b) Program inventory berbasis web ini merupakan sebuah sistem informasi yang dapat membantu akivitas distribusi dan logistik serta proses inventarisasi pada PT Sarana Abadi Makmur Bersama menjadi lebih efisien.

\section{Saran}

Untuk pengembangan lebih lanjut, maka penulis memberikan saran yang mungkin dapat membantu proses pengolahan data pada PT Sarana Abadi Makmur Bersama untuk masa yang akan datang, yaitu:

a) Pemberian pelatihan sebelum penggunaan website ini.

b) Dilakukannya pemeliharaan dan perawatan secara berkala terhadap perangkat lunak (software) dan 
perangkat keras (hardware) agar informasi yang disampaikan dapat cepat untuk diakses.

\section{DAFTAR PUSTAKA}

Andriansyah, D. (2016). Sistem Informasi Pendaftaran Event Dengan PHP Untuk Panduan Skripsi. Cirebon: CV ASFA Solution.

Frieyadie. (2015). PEMBANGUNAN SISTEM INFORMASI INVENTORY MENGGUNAKAN LINEAR SEQUENTIAL MODEL UNTUK PENINGKATAN LAYANAN INVENTORY BARANG. Jurnal Techo Nusa Mandiri, XII(1), 203$207 . \quad$ Retrieved from https://media.neliti.com/media/publication s/227429-pembangunan-sisteminformasi-inventory-m-c1dd7902.pdf

Kosasi, S., \& Yuliani, I. D. A. E. (2015). Simetris : jurnal teknik mesin, elektro dan ilmu komputer. Simetris: Jurnal Teknik Mesin, Elektro dan IImu Komputer (Vol. 6). Retrieved from http://jurnal.umk.ac.id/index.php/simet/arti cle/view/234/231

Kusuma, H. (2009). Manajemen Produksi:Perencanaan dan Pengendalian Produksi (4th ed.). Yogyakarta: Andi.

Mersiana, D., \& Purwandari, N. (2017). Aplikasi Sistem Inventory Berbasis Web Pada PT. Kreasinar Inticipta Nuansa. Kalbiscentia, 4(2), 106-117. Retrieved from

http://research.kalbis.ac.id/Research/File s/Article/Full/BUVTH8JSE2RPF5N8MVG HV53P6.pdf

Prasetio, R. T. (2014). INVENTORY CONTROL USING STATISTICS FORECASTING ON MANUFACTURE COMPANY. Jurnal Informatika (Vol. II). Retrieved from https://ejournal.bsi.ac.id/ejurnal/index.php /ji/article/viewFile/45/23

Sukamto, R. A., \& Shalahudin, M. (2016). Rekayasa Perangkat Lunak. Bandung: Informatika Bandung. 